\title{
Effect of axial and shear prehardening on fatigue behaviour of the 304L SS
}

\author{
Adel Belattar ${ }^{\mathrm{a}}$, Clément Killer and Lakhdar Taleb \\ INSA Rouen/GPM, UMR CNRS 6634, BP. 08, Avenue de l'Université, 76800 St. Etienne du Rouvray, \\ France
}

\begin{abstract}
Effects of cyclic prehardening in axial and shear direction at zero mean stress and/or strain on the cyclic behavior and fatigue of an austenitic stainless steel $304 \mathrm{~L}$ is investigated at room temperature. Fatigue results tests showed that prehardening significantly reduces the fatigue life of the material. Fatigue life decreasing is associated with formation of heterogeneous dislocation structures inherited from the prehardening.
\end{abstract}

\section{Introduction}

Prehardening due to manufacturing process, post-treatments and service conditions can have a substantial effect on the cyclic and fatigue behavior of 304L stainless steel. To determine the required parameters for the reliable and accurate prediction of fatigue life, the effect of this prior straining on the subsequent cyclic behavior and fatigue, with or without mean stress and strain, must be considered. Several previous works were interested in the prehardening effects on the fatigue life of metallic materials [1,2]; where, mean stress can be positive or negative during fatigue tests. Therefore, our objective here is to study the isolate effect of a prehardening in axial and shear direction on the fatigue at zero mean stress and/or strain.

\section{Procedures, results and discussion}

The cyclic behavior is investigated through cyclic tension-compression (ACP_1.5\%) as well as shear (SCP_1.5\%) strain control cycles carried out in four loading sequences with increasing/decreasing Von-Mises equivalent amplitudes on the same specimen. In the first one, the strain amplitude was progressively increased until the maximum level (1.5\%). Once at saturation, decreasing strain amplitudes (inverse loading path) was applied, this sequence was then the second one. The third and the fourth sequences are the same as the first and the second ones respectively. The effect of prehardening on fatigue is studied through fully-reversed axial strain controlled tests conducted at different amplitudes $(0.22 \%, 0.36 \%$ and $0.5 \%)$ on specimens initially subjected to the four sequences described above.

\footnotetext{
${ }^{a}$ Corresponding author: adel.belattar@insa-rouen.fr
}

This is an Open Access article distributed under the terms of the Creative Commons Attribution License 4.0, which permits unrestricted use, distribution, and reproduction in any medium, provided the original work is properly cited. 

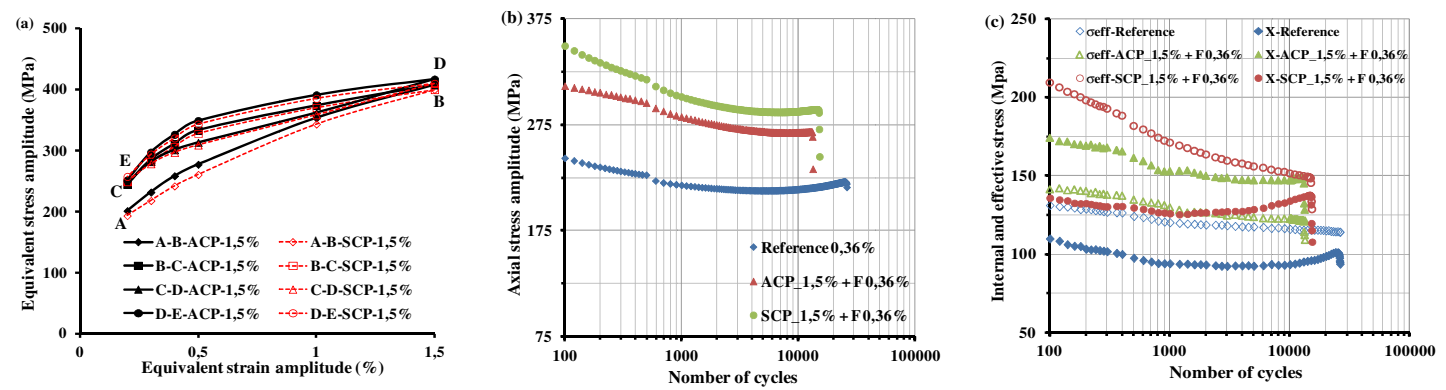

Figure 1. (a) Cyclic stress-strain curve in axial shear load direction, (b) stress amplitude evolution during fatigue tests at $0.36 \%$ and (c) evolution internal and effective stress during the fatigue tests at $0.36 \%$.
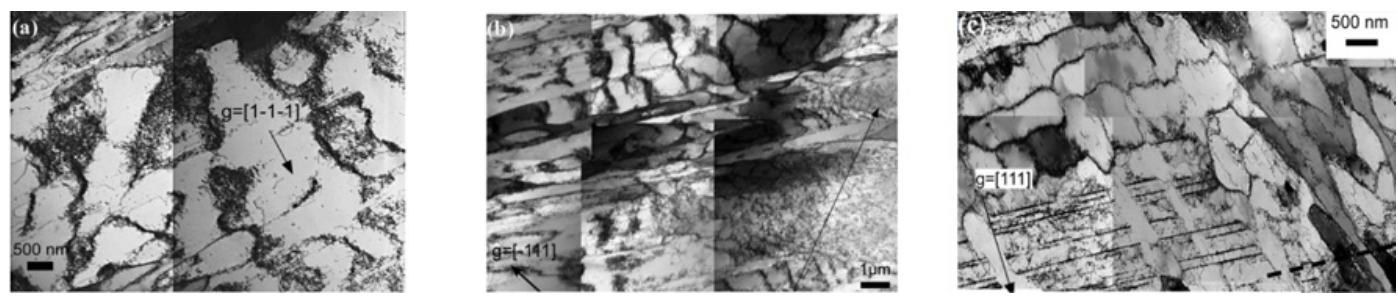

Figure 2. Microstructures of fatigue samples solicited at 0.36\%: (a) reference sample, (b) after axial prehardening and (c) after shear prehardening.

The chosen prehardening process has the main advantage to ensure a progressive come back to the origin which ensure zero mean stress and strain during the subsequent fatigue tests.

Cyclic curve for the second sequence (BC) was higher than that of the first sequence (AB) (Fig. 1a). However, the difference between the third and the fourth cyclic curves with the second one is relatively small. Therefore, it seems that the behavior of the material has a tendency to stabilize. Furthermore, stress-strain responses show that cyclic curve is the same in both load directions.

Figure $1 \mathrm{~b}$ shows the stress amplitude evolution during the fatigue tests for reference, axial prehardened and shear prehardened samples. For the sake of conciseness, only the results of $0.36 \%$ strain amplitude are shown (the two other strain amplitude are similar). Fatigue results tests shows that prehardening significantly reduces the fatigue life of the material. Furthermore, it seems that the increase of the strain amplitude in the fatigue test decreases the effect of prehardening. However, axial prehardening sequence leads to larger fatigue life reduction than in torsion. Stress amplitude evolution of prehardened samples shows that stress level is larger compared to the reference one during the fatigue step with a larger increase in shear preloading direction could be due to cross-path effect [3]. Figure 1c shows the internal stress $X$ (internal stress) and effective stress $\left(\sigma_{\text {eff }}\right)$ analyses during fatigue phase. Axial prehardening implies a significant increase in internal stress level. In the case of shear prehardening, effective stress was significantly increased compared to the reference sample due to the cross-path effect.

To understand the mechanisms responsible for prehardening effect, microstructure analyses were performed by TEM. After prehardening, dislocation structures such as veins, PSB or cells are typical of the largest strain amplitude and are not recovered during the cycles of lower strain amplitude. This heterogeneous dislocation structures inherited from the prehardening phase are responsible for the increase in stress level during the fatigue stage together with an early strain localization linked to the decrease in fatigue life. For axial preloading direction, cells are observed in the larger fraction number 
of deformed grains compared to shearing preloading direction indicates a larger strain localisation. Microstructures observation shows that dislocation structures evolutions are in good agreement with internal stress and effective stress analyses following the Mughrabi models [4].

\section{References}

[1] Doquet, V. and S. Taheri, Revue Française de Mécanique, 2000: p. 28-33

[2] Colin, J., A. Fatemi, and S. Taheri, J. of Eng. Mater. and Tech. 2010. 132(2): p. 021008-13

[3] Taleb, L. and A. Hauet, Inter. J. of Plas. 2009. 25(7): p. 1359-1385

[4] Mughrabi, H., 1983. 31(9): p. 1367-1379 